\title{
Evaluation of two regimens to immobilise the knee after injections of yttrium-90
}

\author{
J WINFIELD, J C W CRAWLEY, E A HUDSON, M FISHER, J M GUMPEL
}

British Medical fournal, 1979, 1, 986-987

\section{Summary and conclusions}

Two regimens to immobilise the knee after injection were compared in patients receiving intra-articular yttrium90 for persistent synovitis of the knee, the patients being randomly allocated to receive either complete bed rest or full mobilisation with the affected knee in a firm splint. There was no difference in the percentage of the radioisotope retained in the knee or in that taken up by other tissues between the two regimens.

It is concluded that after intra-articular injections of yttrium-90 strict bed rest in hospital is unnecessary.

\section{Introduction}

Immobilising the knee after an injection of yttrium-90 appears to reduce leakage of the radioisotope from the joint ${ }^{1}$; therapeutic irradiation is increased while irradiation of regional lymph nodes and other tissues is reduced ${ }^{2}$. Chromosomal damage in peripheral blood lymphocytes after intra-articular irradiation may be reduced with immobilisation, ${ }^{3-5}$ probably because the uptake of yttrium- 90 by regional lymph nodes is reduced. Many different immobilisation regimens are used, ranging from relative rest for three days as inpatients to encasing the knee in plaster-of-Paris for five days. As the scientific basis for these various regimens has not been established we have carried out a study to see whether strict bed rest is necessary.

\section{Patients and methods}

We studied 47 patients with persistent synovitis of the knee(s) routinely admitted for treatment with yttrium-90. The synovitis was part of generalised rheumatoid arthritis in $\mathbf{4 0}$ patients; monoarticular rheumatoid arthritis in two; psoriatic arthritis in two; and recurrent hydroarthrosis in two; and was associated with ulcerative colitis in one. In 32 patients only one knee required treatment; these patients were randomly allocated to one of two immobilisation regimensnamely, complete bed rest or mobilisation in a splint. Of the 15 patients who had bilateral knee injections, 14 were allocated to bed rest while one was mobilised. Each patient was scanned with a quantitative hybrid whole-body scanner ${ }^{6}$ after injection and 48 hours later. The amount of isotope retained in the knee was calculated as a percentage of the quantity shown in the original scan, as was the uptake in other organs. Patients allocated to complete bed rest remained in bed until after the second scan, using a commode when necessary. The knees were bandaged with a light crêpe bandage.

\footnotetext{
Northwick Park Hospital and Clinical Research Centre, Harrow, Middlesex HA1 3UJ

J WINFIELD, MB, MRCP, registrar, rheumatic diseases study group (present appointment: senior registrar, Middlesex Hospital, London W1) J C W CRAWLEY, CENG, MIEE, MRC scientist, division of isotopes

E A HUDSON, MD, consultant cytologist, department of histopathology M FISHER, BSC, principal physicist, division of isotopes

J M GUMPEL, BM, MRCP, consultant physician, rheumatic diseases study group
}

Patients in the mobilisation group were encouraged to be fully mobile after the first scan and wore a lightweight plastic or metal back slab on the injected limb secured by a fastening high on the thigh and another just above the ankle.

Results of paired chromosomal studies before and at least six weeks after injection in 11 patients with only one treated knee who had not undergone previous known radiotherapy were independently analysed. Chromosome breaks, dicentric chromosomes, and ring chromosomes were recorded ${ }^{7}$; the results were expressed as the mean increase in the number of dicentrics (dicentric and ring chromosomes) $/ 100 \mathrm{cells} / \mathrm{mCi}$ of yttrium-90 administered.

\section{Results}

We found no difference in the percentage of isotope retained in the treated joint or in that taken up by the liver, lymph nodes, or spleen between the two groups (table). The spontaneous variation in retention found in pairs of knees treated identically was comparable with that found in single knees whether splinted or rested (figure).

Mean retention of yttrium-90 in knee and extra-articular spread (\%)

\begin{tabular}{lcc}
\hline & $\begin{array}{c}\text { Mobilised in knee } \\
\text { splint (22 knees) }\end{array}$ & $\begin{array}{c}\text { Complete bed } \\
\text { rest (40 knees) }\end{array}$ \\
\hline Retention in knee after 48 hours & 91.2 & 90.4 \\
Uptake by regional lymph nodes & 2.3 & 2.3 \\
Uptake by liver and spleen & 1.7 & 1.6 \\
\hline
\end{tabular}

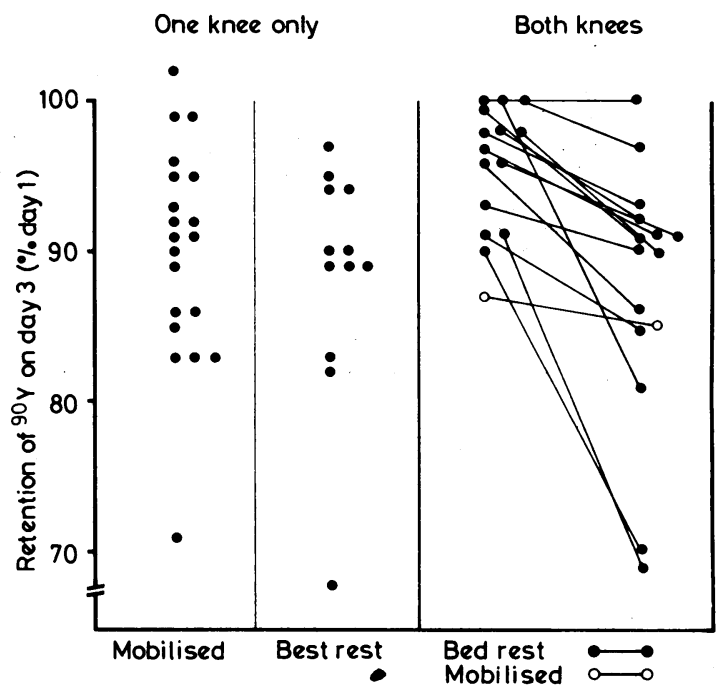

Amount of yttrium-90 remaining in knee after 48 hours as percentage of that shown on original scan according to whether patient was mobilised or given bed rest. In cases in which both knees were injected the knee with better retention is shown in first column.

were studied.

Chromosomal damage was comparable in both groups of patients. There was a net increase of 0.16 dicentrics $/ 100$ cells $/ \mathrm{mCi}$ in six mobilised patients, and of 0.14 dicentrics $/ 100$ cells $/ \mathrm{mCi}$ in five rested patients. 


\section{Discussion}

Radiosynoviorthosis aims at satisfactory irradiation of the synovium with minimal irradiation of other tissues. Of the yttrium radiocolloids, the silicate is best retained in the $\mathrm{knee}^{8}$ and is associated with least chromosomal damage. ${ }^{4}$ Further attempts to reduce extra-articular leakage have included using longer periods of bed rest and encasing the limb in plaster-ofParis after injection, which considerably increase the nursing work load and the patient's discomfort.

This study has shown that a firm, light splint on a mobilised patient minimises extra-articular spread. The chromosomal damage observed in mobilised patients is comparable with that found in other studies of fully immobilised patients. ${ }^{4}$

We thank Dr Norman Veall for his continuing encouragement and support, Mr D G Altman for statistical advice, and Mr D Hinge for technical help.

\section{References}

1 Oka, M et al, Acta Rheumatologica Scandinavica, 1971, 17, 148.

2 De la Chapelle, A, et al, Annals of the Rheumatic Diseases, 1972, 31, 508.

3 Jalava, S, and Salonius, A-L, Lancet, 1974, 1, 807.

4 Gumpel, J M, and Stevenson, A C, Rheumatology and Rehabilitation, 1975, $14,7$.

5 Lloyd, D C, and Reeder, E J, Lancet, 1978, 1, 617.

${ }^{6}$ Crawley, J C W, and Gibbs, G P, in Medical Radionuclide Imaging, Vol I, p 369. Vienna, International Atomic Energy Agency, 1977.

7 Stevenson, A C, et al, Annals of the Rheumatic Diseases, 1973, 32, 112.

8 Gumpel, J M, et al, British fournal of Radiology, 1975, 48, 377.

(Accepted 26 February 1979)

\section{SHORT REPORTS}

\section{Air embolism after accidental removal of intravenous catheter}

Serious and even fatal complications of central venous catheterisation have often been described but remain little appreciated. We report a case of air embolism that occurred in unusual circumstances.

\section{Case report}

A 38-year-old woman with a long history of depression was admitted to our intensive care unit after an overdose of drugs. She was deeply unconscious with an unstable cardiac rhythm and shortly after admission developed ventricular tachycardia leading to cardiac arrest. She was intubated and ventilated with oxygen and was successfully resuscitated after 15 minutes of external cardiac massage and electrical defibrillation. Ventilation was continued and over the next few days her consciousness improved. Initially she had a peripheral venous drip, but this tissued, so an intravenous catheter was substituted to permit measurement of central venous pressure. It was inserted via an introducer cannula into the right internal jugular. Both the catheter and the introducer were stitched firmly to the skin to prevent accidental removal.

Five days after the cardiac arrest we attempted to wean the patient off the ventilator. She was awake and co-operative, but after an hour sitting up and breathing spontaneously with her nasotracheal tube still in place she became confused and began pulling at the nasogastric tube, endotracheal tube, and central venous line. As her colour deteriorated we decided to resume ventilation. In her confusion she suddenly pulled out the venous catheter, leaving the introducer in the vein. Despite being immediately laid head down on her left side she again suffered cardiac arrest, presumably due to massive air embolus. The electrocardiogram showed acute right heart strain. She was again resuscitated but over three months later remained unconscious, breathing spontaneously but with all the other clinical signs of brain death.

\section{Comment}

This case demonstrates the dramatic effect of connecting the internal jugular vein to atmosphere via a 13-gauge introducer cannula; this has a bore of $1.6 \mathrm{~mm}$. The catheter had a male Luer hub, which had originally been firmly engaged in the female hub of the introducer. Nevertheless, the patient disconnected them. The complication might have been prevented by using a different type of catheter. It is feasible to use a long $(15 \mathrm{~cm})$ cannula in the right internal jugular vein, passing down the right innominate vein into the superior vena cava. Alternatively, a catheter may be introduced over a guide by the Seldinger technique. In either case a stiff catheter with a sharp, tapered end must be used, with the serious risk of perforating the great veins. In our unit we usually use a soft, flexible $20 \mathrm{~cm}$ catheter with a rounded end and side holes, which is unlikely to damage veins. ${ }^{1}$ This type of catheter is inserted through a plastic cannula which remains in place around the external end of the catheter, providing valuable reinforcement of the vulnerable junction of the catheter with its hub. Correct location of the catheter depends in part on a firm attachment to the hub of the cannula, so that the two will move only as a single unit. We strongly recommend withdrawing this combined unit so that the tip of the introducer no longer lies within the vein, thus preventing the possibility of air entering if the catheter alone is removed. We also believe that catheters should always be firmly stitched in place and that all devices attached to them, such as drip sets or central venous pressure manometers, should have locking hubs.

$\mathrm{Mr} \mathrm{H} \mathrm{G}$ Wallace, who makes our venous catheters, has produced a modified design incorporating a locking ring on the catheter hub, which is also much easier to stitch down. This should prevent the catheter being removed accidentally without also removing the introducer (see figure).

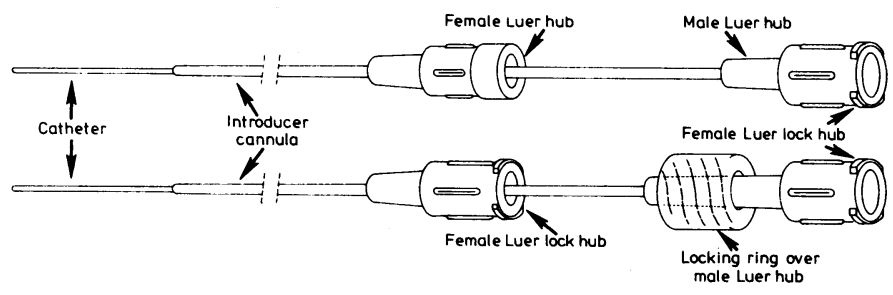

Designs of catheter and introducer. Top: Present design, with simple malefemale junction between catheter and introducer. Bottom: New design with addition of locking ring.

We are grateful to $\mathrm{Mr} \mathrm{H} \mathrm{G} \mathrm{Wallace} \mathrm{for} \mathrm{his} \mathrm{prompt} \mathrm{response} \mathrm{in} \mathrm{modifying}$ the design of the catheter and introducer.

${ }^{1}$ Farman, J V, British fournal of Clinical Equipment, 1978, 3, 210.

(Accepted 9 February 1979)

Addenbrooke's Hospital, Cambridge CB2 2QQ

SHEENA M ROSS, MB, DRCOG, registrar in anaesthetics PETER S FREEDMAN, MB, MRCP, lecturer in medicine JOHN V FARMAN, BM, FFARCS, consultant anaesthetist

\section{Digoxin dosage in infants}

In infants digoxin is a life-saving medication, but the demarcation line between therapeutic and toxic doses is narrow, and the clinical response to the drug varies greatly. Hence it is crucial to assess how the child has responded to the first dose before giving any more.

\section{Regimen}

At the Radcliffe Infirmary our practice is to use digoxin injection paediatric $B P, 100 \mathrm{mg} / \mathrm{l}$. The initial loading dose advised is $10 \mu \mathrm{g} / \mathrm{kg}(0.1 \mathrm{ml} / \mathrm{kg})$ intramuscularly every four hours to a total of four to six doses-that is, 